\title{
Chronic Liver Diseases- Experience at Tertiary Care Centre of Northern India
}

\author{
Parveen Malhotra ${ }^{1 *}$, Vani Malhotra ${ }^{1}$, Yogesh Sanwariya ${ }^{1}$, Isha Pahuja ${ }^{1}$, Ajay Chugh ${ }^{1}$, Akshay ${ }^{1}$ \\ Department of Medical Gastroenterology and Obstetrics \& Gynecology, PGIMS, Haryana India.
}

*Corresponding author: Parveen Malhotra, Department of Medical Gastroenterology and Obstetrics \& Gynecology, PGIMS, Haryana India.

Received date: July 27, 2021 Accepted date: August 20, 2021 Published date: September 06, 2021

Citation: Malhotra P., Malhotra V., Sanwariya Y., Pahuja I., Chugh A., Akshay (2021) Spectrum of Chronic Liver Diseases in Northern India. J. Gastroenterology Pancreatology and Hepatobilary Disorders. 5(5) DOI: 10.31579/2641-5194/042

Copyright: (c) 2021, Parveen Malhotra, This is an open access article distributed under the Creative Commons Attribution License, which permits unrestricted use, distribution, and reproduction in any medium, provided the original work is properly cited.

\begin{abstract}
Introduction: It is important to determine the epidemiological factors like etiology, age, sex, mode of clinical presentation and pattern of development of complications of chronic liver disease, so as to design optimal and cost effective preventive and treatment strategies for the same.
\end{abstract}

Aim: To determine etiology of Chronic liver disease in Northern India.

Material and Methods: This was a prospective study done at Medical Gastroenterology Department, PGIMS,Rohtak conducted over a period of ten years i.e. 01.01.2011 to 31.12.2020, on 1000 confirmed patients of chronic liver disease (CLD).

Results: The most common etiology seen was Alcoholic liver disease (48.9\%), followed by Nonalcoholic liver disease (26.4\%), Chronic Hepatitis B (12.3\%), Chronic Hepatitis C (9\%), Cryptogenic (2.7\%) and Autoimmune liver disease related $(0.7 \%)$.

Conclusion: The present study reveals that alcohol is most common cause of chronic liver disease in Northern India. The males of middle age group with rural background are at significant risk of developing CLD, thus requiring immediate social and medical intervention.

Keywords: chronic liver disease; alcoholic liver disease; Non-alcoholic fatty liver disease; hepatitis B; hepatitis C; autoimmune liver disease; cryptogenic;

\section{Introduction}

There are few Indian studies on clinical aspects of chronic liver disease (CLD) like etiology, natural history, clinical presentation, treatment recommendations and its effect of public health [1-3] but its changing trends and burden of morbidity and mortality has not been analyzed in depth as compared to developed countries [3-5]. The concept behind examining the trend of the disease over a time period is to observe the variation of its different aspect and determine the status of country's public health system [6-7]. The analysis of the exact disease burden of the country assists in cost effective and optimal use of control measures taken by the government and it also provide the disease scenario particularly in developing country like India [7]. The lack of exact data hinders development of effective policies which can help the patients to get rid of the disease such as optimal use of liver transplant [7]. Alcoholic liver disease has taken lead in causing chronic liver disease in India, followed by Nonalcoholic fatty liver disease and chronic hepatitis B \& C. The government bears huge expenditure on outdoor as well as Indoor basis treatment of these CLD patients which can be reduced substantially by investing on preventive strategies for developing chronic liver disease.

\section{Aim}

To determine etiology of chronic liver disease in Northern India.

\section{Material and Methods}

This was a prospective study done at Medical Gastroenterology Department, PGIMS,Rohtak conducted over a period of ten years i.e. 01.01.2011 to 31.12.2020, on 1000 confirmed cases of chronic liver disease. The patients who visited the Medical Gastroenterology Department in last ten years and were confirmed to be having CLD on ultrasonogram , Fibroscan and biochemical tests, after proper consent werer enrolled in the study. Their detailed records were collected regarding epidemiological profile, aetiological factors and clinical spectrum and were followed regularly. The detailed clinical examination and laboratory investigations were done like complete blood counts, liver function tests , kidney function tests, serum electrolytes, coagulation parameters (PT, INR), blood sugar, autoimmune profile, Hbs Ag, anti HIV antibody, anti HCV antibody, HBV DNA Quantitative \& HCV RNA Quantitative whereever indicated, ultrasonogram abdomen, chest $\mathrm{x}$ ray PA view ,ascitic fluid - TLC, DLC, cultures, SAAG, Upper GI endoscopy 
for esophageal varices and portal hypertensive gastropathy, Triple phase CT scan of abdomen and Fibroscan.

\section{Observations}

The most common etiology determined was Alcoholic liver disease (48.9\%), followed by Nonalcoholic liver disease (26.4\%), Chronic Hepatitis B (12.3\%), Chronic Hepatitis C (9\%), Cryptogenic (2.7\%) and Autoimmune liver disease related $(0.7 \%)$. On individual analysis of Alcoholic liver disease, out of total 489 patients, 482 (98.56\%) were male and 7 patients $(1.44 \%)$ were female. The reason behind this may be that significant percentage of alcoholic patients belong to rural areas of Northern India where habit of alcohol intake is minimal, so as to reach stage of chronic liver disease. The alcohol consumption in females is more commonly seen in affluent class of big cities, who usually seek consultation in private set up, instead of government set up where this study was conducted. Out of total 489 patients, 288 patients $(58.89 \%)$ belonged to rural areas and 201 patients $(41.11 \%)$ belonged to urban areas. On analyzing age distribution curve, none patient was seen in $0-20$ years of age after which sharp rise was noted between 20-40 years i.e. 152 patients $(31.08 \%)$ and peak was seen between $40-60$ years i.e. 274 patients $(56.03 \%)$, followed by decline in $60-80$ years i.e. 63 patients $(12.88 \%)$. One important observation from the study made was that, out of total 489 patients, 416 patients $(85.07 \%)$ started consuming alcohol due to pressure from friends and 73 patients (14.93\%) imbibed the habit of drinking from other family members like father and elder brother. Maximum number of patients started drinking between 20-30 years of age group i.e. 254 patients $(51.94 \%)$.

On analyzing Non Alcoholic Fatty liver disease group, out of total 264 patients, $157(59.46 \%)$ were male and 107 patients (40.54\%) were female. Out of total 264 patients, 141 patients $(53.40 \%)$ belonged to rural areas and 123 patients $(46 \%)$ belonged to urban areas. On analyzing age distribution curve, 6 patients $(2.27 \%)$ were seen in $0-20$ years of age after which sharp rise was noted between 20-40 years i.e. 66 patients $(25 \%)$ and peak was seen between $40-60$ years i.e. 132 patients (50\%), followed by decline in $60-80$ years i.e. 57 patients $(21.59 \%)$.

On individual analysis of Chronic Hepatitis B related group of CLD, out of total 123 patients, $101(82.11 \%)$ were male and 22 patients $(17.88 \%)$ were female. Out of these 123 patients, 86 patients $(69.91 \%)$ belonged to rural areas and 37 patients $(30.09 \%)$ belonged to urban areas. On analyzing age distribution curve, 3 patients $(2.43 \%)$ were seen in $0-20$ years of age after which sharp rise was noted between 20-40 years i.e. 30 patients $(24.39 \%)$ and peak was seen between $40-60$ years i.e. 57 patients (46.34\%), followed by decline in $60-80$ years i.e. 33 patients $(26.82 \%)$.

The analysis of Chronic hepatitis $\mathrm{C}$ related CLD group revealed that out of total 90 patients, $49(54.44 \%)$ were male and 41 patients $(45.55 \%)$ were female. Out of these total 90 patients, 65 (72.22\%) belonged to rural areas and 25 patients $(27.78 \%)$ belonged to urban areas. On analyzing age distribution curve, none patient was seen in 0-20 years of age after which sharp rise was noted between $20-40$ years i.e. 13 patients $(14.44 \%)$ and peak was seen between $40-60$ years i.e. 56 patients $(62.22 \%)$, followed by decline in 60-80 years age group i.e. 21 patients $(23.33 \%)$.

On individual analysis of Autoimmune liver disease group, out of total 7 patients, $5(71.42 \%)$ were male and 2 patients $(28.57 \%)$ were female and 4 patients $(57.14 \%)$ belonged to rural areas and 3 patients $(42.85 \%)$ belonged to urban areas. On analyzing age distribution curve, three patients $(42.85 \%)$ were seen in $0-20$ years of age and four patients $(57.14 \%)$ were seen between $20-40$ years age group and none of the patient belonged to above 40 years of age group.

In Cryptogenic group, out of total 27 patients, 12 (44.44\%) were male and 15 patients $(55.55 \%)$ were female and in them 18 patients $(66.66 \%)$ belonged to rural areas and 9 patients $(33.33 \%)$ belonged to urban areas. On analyzing age distribution curve, none patient was seen in 0-20 years of age, 7 patients $(25.92 \%)$ were seen in 20-40 years age group, 12 patients $(44.44 \%)$ in $40-60$ years age group and 8 patients $(29.62 \%)$ in $60-80$ years of age group.

\begin{tabular}{|l|r|}
\hline Category & Number of Patients \\
\hline ALD & 489 \\
\hline NAFLD & 264 \\
\hline HEP-B related & 123 \\
\hline HEP-C related & 90 \\
\hline Autoimmune & 7 \\
\hline Cryptogenic & 27 \\
\hline
\end{tabular}

Table 1- Showing Distribution of one Thousand CLD Patients on Basis of Etiology

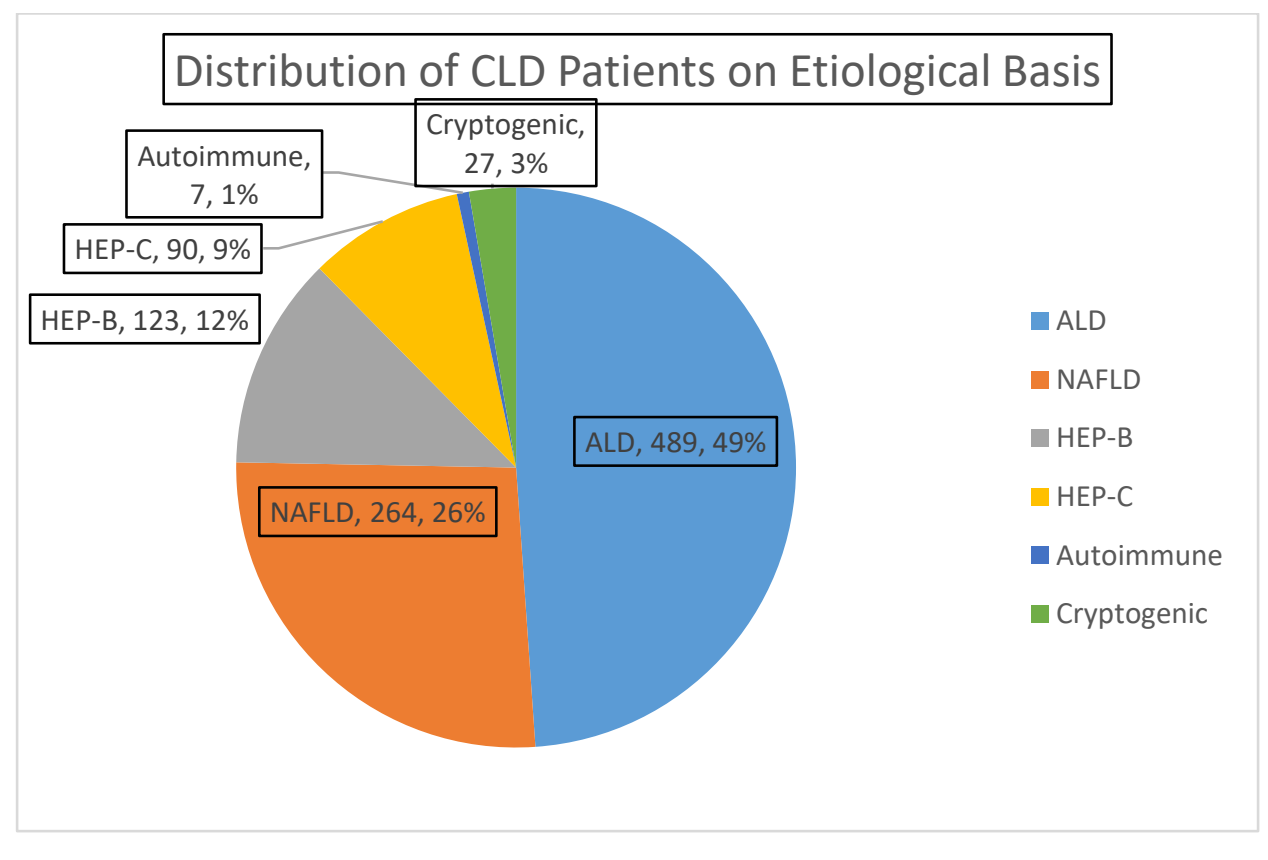


Figure 1- Pie Chart Showing Distribution of CLD Patients on Basis of Etiology.

\begin{tabular}{|l|r|r|r|r|r|r|}
\hline Sex & \multicolumn{1}{|c|}{ ALD } & NAFLD & \multicolumn{1}{l|}{ HEP-B } & Hep-C & \multicolumn{1}{l|}{ Autoimmune } & Cryptogenic \\
\hline Male & 482 & 157 & 101 & 49 & 2 & 12 \\
\hline Female & 7 & 107 & 22 & 41 & & 5 \\
\hline
\end{tabular}

Table 2- Sex Distribution of CLD Patients of Different Categories.

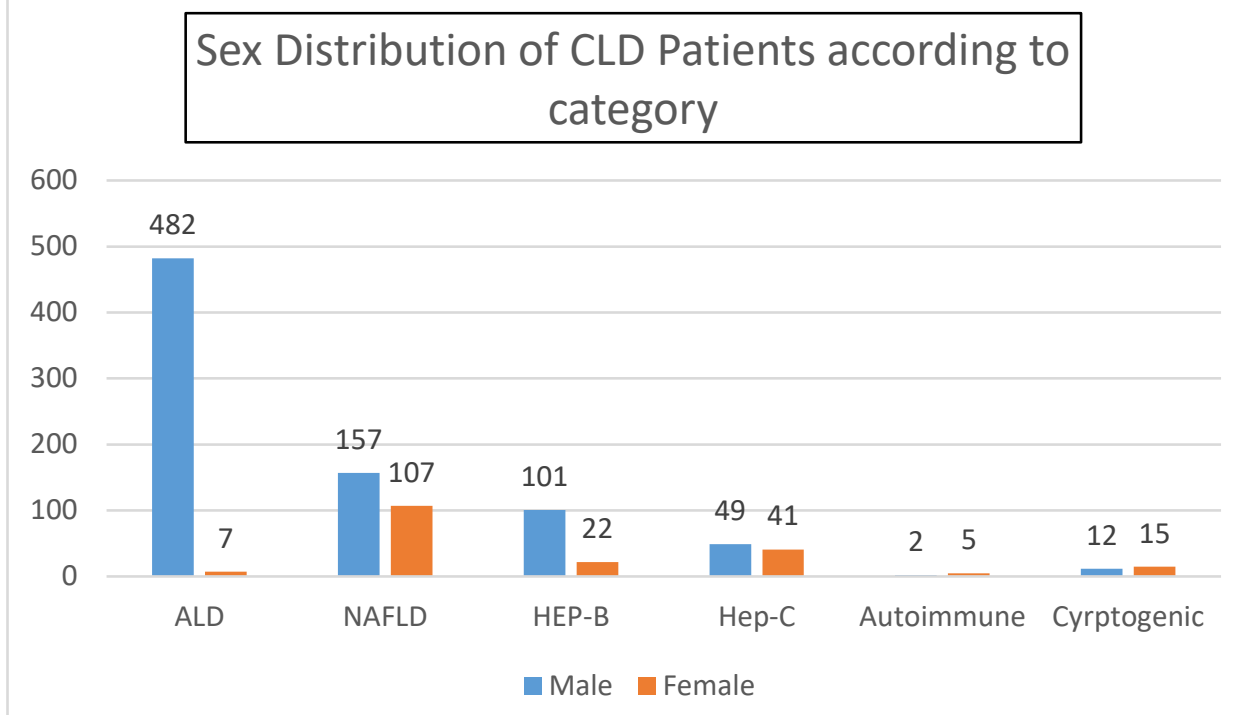

Figure 2- Sex Distribution of CLD Patients

\begin{tabular}{|l|r|r|r|r|r|r|}
\hline Residence & \multicolumn{1}{|l|}{ ALD } & \multicolumn{1}{l|}{ NAFLD } & \multicolumn{1}{l|}{ HEP-B } & \multicolumn{1}{l|}{ Hep-C } & \multicolumn{1}{l|}{ Autoimmune } & Cryptogenic \\
\hline Rural & 288 & 141 & 86 & 65 & 4 & 18 \\
\hline Urban & 201 & 123 & 37 & 25 & 3 & 9 \\
\hline
\end{tabular}

Table 3- Rural and Urban Distribution of CLD Patients

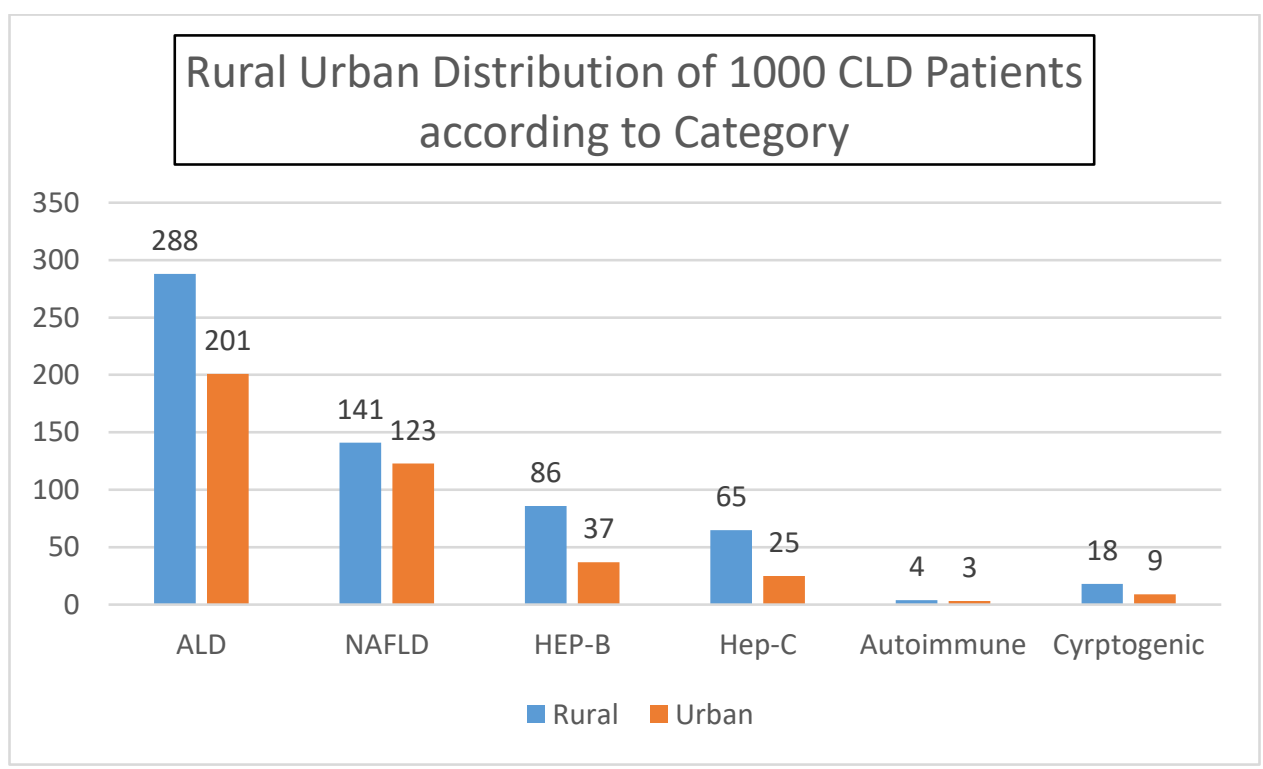

Figure 3- Showing Rural and Urban Distribution of CLD Patients

\begin{tabular}{|c|c|c|c|c|c|c|}
\hline & & $\begin{array}{c}\text { Hepatitis B } \\
\text { Related CLD }\end{array}$ & $\begin{array}{c}\text { Hepatitis C } \\
\text { Related CLD }\end{array}$ & Autoimmune & Cryptogenic \\
\hline
\end{tabular}




\begin{tabular}{|c|c|c|c|c|c|c|}
\hline $0-20$ & 0 & 6 & 3 & 0 & 3 & 0 \\
\hline $20-40$ & 152 & 66 & 30 & 13 & 4 & 7 \\
\hline $40-60$ & 274 & 132 & 57 & 56 & 0 & 12 \\
\hline $60-80$ & 63 & 57 & 33 & 21 & 0 & 12 \\
\hline $80-100$ & 1 & 3 & 0 & 0 & 0 & 0 \\
\hline
\end{tabular}

Table 4- Age Distribution of CLD Patients

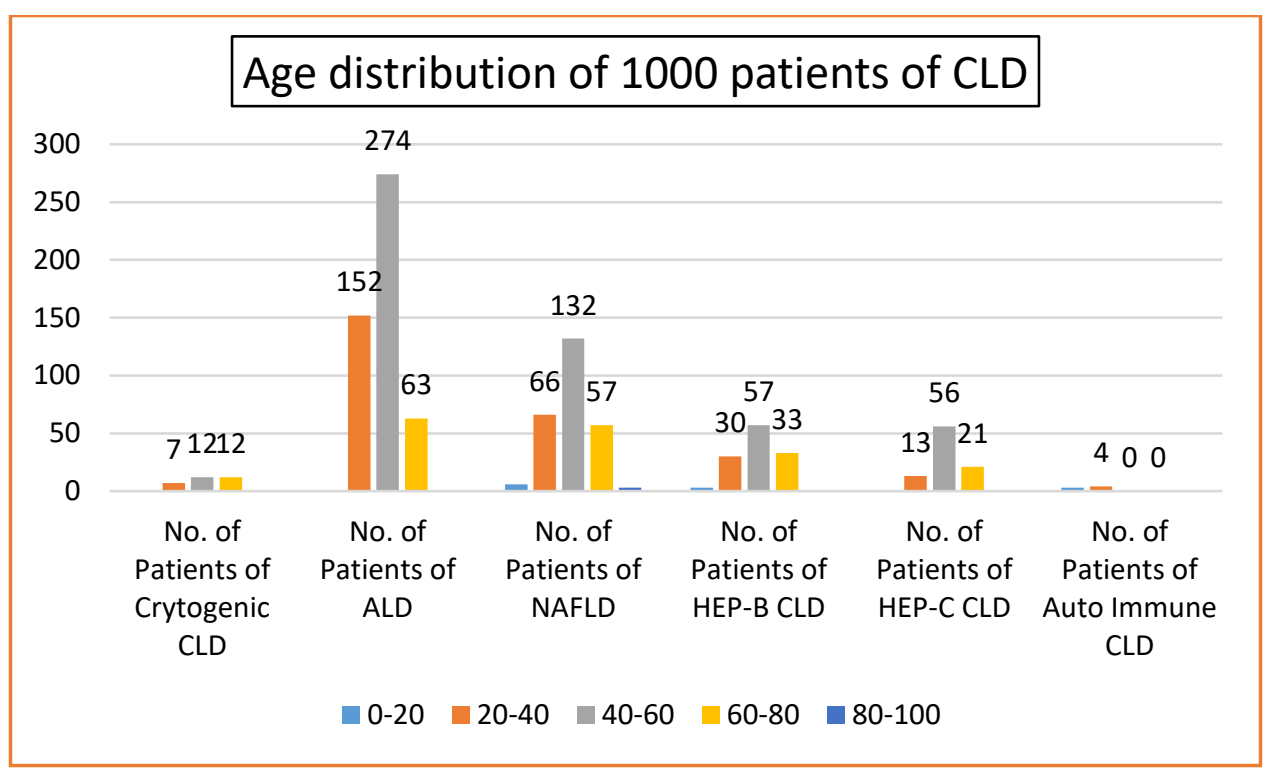

Figure 4- Rural and Urban Distribution of CLD Patients

\section{Discussion}

This was hospital based study with aim of determining the etiology of chronic liver disease in our region. Male predominance was seen in all the various groups of liver diseases except autoimmune and cryptogenic group. The majority of patients in all the groups were seen in middle age group, which is similar to the study done by Pal et al at Kolkata where $79 \%$ of patients were male and $54 \%$ of patients belonged to age group 31 to 50 years indicating that CLD is more common in male suggesting high risk of exposure to causative factors [8]. The most common etiology seen in our study group was Alcoholic liver disease (48.9\%), followed by Nonalcoholic liver disease (26.4\%), Chronic Hepatitis B (12.3\%), Chronic Hepatitis C (9\%), Cryptogenic (2.7\%) and Autoimmune liver disease related $(0.7 \%)$ which is in contrast to Western Countries where in a large multicenter study done by Stroffoline et al searching for the etiology of chronic hepatitis in Italy studied 6210 patients consecutively admitted to 79 hospitals throughout Italy. They found chronic hepatitis $\mathrm{C}$ $(62.6 \%)$ as most common etiological factor followed by chronic hepatitis B in $9.2 \%$ [9]. Similarly our study is not in line with study conducted by Velosa et al from Portugal in which out of 988 patients of CLD, viral etiology was seen in $82 \%$, metabolic in $2 \%$, biliary in $2 \%$, alcoholic in $11 \%$, autoimmune in $1.5 \%$, and idiopathic in $2 \%$. Among viral group, hepatitis B virus infection was determined in $65 \%$, hepatitis $\mathrm{C}$ in $26 \%$ and hepatitis D was found in $8 \%$ [10] which is in alignment with our study as in our results also hepatitis B was more common cause then hepatitis $\mathrm{C}$ in causing CLD. In our study, rural predominance was seen in all the groups of chronic liver disease and NAFLD has become second most common reason for CLD in India because of increasing trend of sedentary life style and contribution from increased number of patients of Diabetes Mellitus. The present study data showed that alcohol is the most common culprit for CLD in Northern India. Further studies will be needed to establish what cause is; high susceptibility of study population to alcohol, high risk behavior of the population, or both for getting advanced CLD due to alcohol in Northern India. In India, under National Viral Hepatitis Control Program (NVHCP), free treatment is being given for hepatitis B \& $\mathrm{C}$ all over India for curbing the menace of these deadly disease. As per results of our research, there is urgent need of taking steps for determining and controlling the factors leading to alcoholic liver disease and Nonalcoholic fatty liver disease because of their significant contribution in total pool of CLD in India. In both of these etiological factors, public awareness on large scale is required because it is well said that prevention is better than cure. The government has to seriously rethink to choose between earnings from sale of alcohol and expenditure being done on management of ALD patients and high number of lives being lost on daily basis. Moreover, Liver transplant which is the only definitive treatment for End Stage liver disease, is beyond reach of majority of Indians due to its limited availability, less number of organ donation and financial constraints. Hence, in developing country like India, aim should be not to make patients reach End stage liver disease and on transplant waitlist.

\section{Conclusion}

Chronic liver disease is common entity in Northeren India with male preponderance and affecting mostly people of middle age group. Alcohol intake is major cause of chronic liver disease, followed by Nonalcoholic fatty liver disease and chronic hepatitis B \& C. Hence government should make future policies and prioritize on basis of contribution of various etiologies in total pool of chronic liver disease in India.

\section{Conflict Of Interest}

The authors disclose that there were no conflict of interest.

\section{References}


1. Bosetti C, Levi F, Lucchini F, Zatonski WA, Negri E, La Vecchia C. (2007) Worldwide mortality from cirrhosis: An update to 2002. J Hepatol. 46:827-39.

2. Dunbar JK, Crombie IK. (2011) The rising tide of liver Cirrhosis mortality in the UK: can its halt be predicted? Alcohol. 46:459-63.

3. McAvoy NC, Hayes PC. (2007) The cirrhosis epidemic in the UK: evaluating the causes in a European context. Expert Rev Gastroenterol Hepatol. 1:41-5.

4. Thomson SJ, Westlake S, Rahman TM, Cowan ML, Majeed A, Maxwell JD et al. (2008) Chronic liver disease: an increasing problem: a study of hospital admission and mortality rates in England, 1979-2005, with particular reference to alcoholic liver disease. Alcohol. 43:416-22.

5. Singh GK, Hoyert DL. (2000) Social epidemiology of chronic liver disease and cirrhosis mortality in the United States,
19351997: trends and differentials by ethnicity, socioeconomic status, and alcohol consumption. Hum Biol. 72:80120.

6. Vong S, Bell BP. (2004) Chronic liver disease mortality in the United States, 1990-1998. Hepatology. 39:476-83.

7. Ray G. (2014) Trends of chronic liver disease in a tertiary care referral hospital in Eastern India. Indian J Public Health. 58:18694.

8. Pal J, Dasgupta S, Agarwal V, Kejariwal D, Roy S, Majumder AK. (2003) Clinical profile of chronic liver diseases in a tertiary care center in Kolkata. Japi. 51: 1173-4.

9. Stroffolini T, Sagnelli E, Mele A, Craxì A, Almasio P. (2004) The etiology of chronic hepatitis in Italy: results from a multicentre national study. Dig Liver Dis. 36:829-33.

10. Velosa J, Ramalho F, Serejo F, Marinho R, de Moura MC. (1993) Chronic hepatitis: The etiological spectrum, The implications for treatment. Acta Med Port. 6:233-8. 
This work is licensed under Creative

Commons Attribution 4.0 License

To Submit Your Article Click Here: Submit Manuscript

DOI: $10.31579 / 2641-5194 / 042$
Ready to submit your research? Choose Auctores and benefit from:

fast, convenient online submission

$>$ rigorous peer review by experienced research in your field

$>$ rapid publication on acceptance

$>$ authors retain copyrights

$>$ unique DOI for all articles

$>$ immediate, unrestricted online access

At Auctores, research is always in progress.

Learn more auctoresonline.org/journals/gastroenterology-pancreatologyand-hepatobilary-disorders 